\title{
Perdas na ensilagem de capim-elefante aditivado com farelo de cacau e cana-de-açúcar
}

[Losses in ensiling of elephantgrass added with cocoa meal and sugarcane]

\author{
F.A. Teixeira ${ }^{1}$, C.M. Veloso ${ }^{2,4}$, A.V. Pires $^{2,4}$, F.F. Silva ${ }^{2,4}$, P.V.N. Nascimento ${ }^{1}$ \\ ${ }^{1}$ Aluno de pós-graduação - UESB - Itapetinga, BA \\ ${ }^{2}$ Departamento de Tecnologia Rural e Animal - UESB - Itapetinga, BA
}

\begin{abstract}
RESUMO
Foram estudados os efeitos da adição de farelo de cacau e de cana-de-açúcar sobre as perdas de silagem de capim-elefante. Utilizou-se um esquema fatorial 2 x 4 , sendo 0 e $15 \%$ de farelo de cacau e $0,15,30$ e $45 \%$ de cana-de-açúcar, com quatro repetições, no delineamento inteiramente ao acaso. O capim-elefante apresentava $29,2 \%$ de matéria seca, e as silagens foram produzidas em silos experimentais de PVC, utilizando-se compactação de $600 \mathrm{~kg}$ de silagem $/ \mathrm{m}^{3}$. A abertura dos silos ocorreu aos 60 dias após a ensilagem, quando foram determinados o teor de nitrogênio amoniacal e o pH das silagens. $\mathrm{O}$ farelo de cacau foi eficaz na redução da umidade e da concentração de nitrogênio amoniacal. Recomenda-se a inclusão de até $22,4 \%$ da cana-de-açúcar, cv-IAC86-2480, na ensilagem de capim-elefante com $29 \%$ de matéria seca, podendo-se aumentar para $45 \%$, desde que se utilizem $15 \%$ de farelo de cacau.
\end{abstract}

Palavras-chave: silagem, fermentação, efluente, nitrogênio amoniacal

\begin{abstract}
The effects of the addition of cocoa meal and sugarcane in the elephant-grass silage losses were studied. A $2 \times 4$ factorial scheme was used, being 0 and 15\% of cocoa meal and $0,15,30$, and $45 \%$ of sugarcane, with four repetitions, in a completely randomized design. The elephant-grass showed $29.2 \%$ of dry matter and the silages were produced in PVC experimental silos, using $600 \mathrm{~kg} / \mathrm{m}^{3}$ silage compaction. The silos were opened 60 days after ensilage, when ammonia nitrogen content and $\mathrm{pH}$ of the silages were determined. Cocoa meal was effective in the reduction of moisture and ammonia nitrogen concentrations. It is recommended the inclusion of up to $22.4 \%$ of the sugar-cane, cv-IAC86-2480, in the elephant-grass ensiling with $29 \%$ of dry matter, which can be increased to $45 \%$, since $15 \%$ of cocoa meal be used.
\end{abstract}

Keywords: silage, ammonia nitrogen, effluent, fermentation

\section{INTRODUÇÃO}

A ensilagem constitui uma das estratégias mais utilizadas para armazenar forragem visando minimizar as perdas na produção dos rebanhos durante os períodos de escassez. Contudo, para que se obtenha uma silagem de boa qualidade, deve-se usar forrageiras que apresentem teores de umidade e quantidade de carboidratos solúveis (CS) adequados, características que são limitantes para ensilagem do capim-elefante (Pennisetum purpureum Schum) que, segundo
Ferrari Jr. e Lavezzo (2001), apresenta, no estádio de melhor valor nutritivo, excesso de umidade. Isso resulta em silagem de baixa qualidade, com grande decomposição protéica, além de elevadas perdas por efluente. Mais ainda, com a maturação, a planta, ainda que haja aumento da produção de matéria seca (MS), fornece um produto de baixo valor nutritivo.

Outras forrageiras, como a cana-de-açúcar, também podem ser ensiladas. Nussio et al. (2003) ressaltaram, contudo, que a produção de

Recebido em 26 de outubro de 2006

Aceito em 17 de dezembro de 2007

Endereço para correspondência (corresponding address)

Av. das Palmeiras, 261 - 45700-000 - Itapetinga, BA

email: ftxzoo@yahoo.com.br 
etanol, em função da alta concentração de CS na cana-de-açúcar, é uma limitação do uso dessa gramínea no processo de ensilagem. Entretanto, ela poderia fornecer carboidratos solúveis em silagens de capim-elefante, quando utilizada como aditivo (Velloso et al., 1973). Woolford (1984) acrescentou que, além da elevada concentração desses carboidratos, o principal fator que possibilita o rápido desenvolvimento das leveduras na silagem de cana-de-açúcar é o baixo teor de MS.

Com a finalidade de melhorar o processo fermentativo da silagem do capim-elefante, já foram testados vários aditivos. Os aditivos ricos em carboidratos não fibrosos, como, o fubá de milho e o melaço em pó, podem ser utilizados em silagens de capim-elefante contendo 15,3\% de MS (Andrade e Melotti, 2004). Outro aditivo, o sabugo de milho, quando usado, reduziu a umidade do capim-elefante ensilado com 15,9\% de MS (Tosi et al., 1999). Bernardino et al. (2005) garantiram que $20 \%$ de casca de café promoveram boa preservação da silagem e eliminaram a produção de efluente, quando foi usado o capim-elefante com $12,4 \%$ de MS. Rodrigues et al. (2005) enfatizaram que valores de 4,7 a 7,6\% de polpa cítrica peletizada foram suficientes para melhorar a qualidade de fermentação.

A decisão pelo tipo de material absorvente depende não somente dos seus efeitos positivos, mas também da sua disponibilidade e viabilidade econômica. Assim, o farelo de cacau, resíduo da retirada da casca das amêndoas (Pires et al., 2002), surge como uma alternativa que, de acordo com Teixeira et al. (2005), é eficiente na redução da umidade da silagem de capimelefante.

Neste trabalho o objetivo foi avaliar os efeitos da adição do farelo de cacau e da cana-de-açúcar sobre as perdas de silagem de capim-elefante.

\section{MATERIAL E MÉTODOS}

$\mathrm{Na}$ pesquisa usaram-se o capim-elefante (Pennisetum purpureum Schum.) cv. Mercker, como forrageira para a ensilagem, e, como aditivos, a cana-de-açúcar (Saccharum officinarum) cv. IAC 86-2480, com teor de carboidratos solúveis igual a 12 graus brix, e o farelo de cacau (Theobroma cacao) (Tab. 1).

Tabela 1. Composição químico-bromatológica do capim-elefante, da cana-de-açúcar e do farelo de cacau

\begin{tabular}{lccc}
\hline Variável & Capim-elefante & Cana-de-açúcar & Farelo de cacau \\
\hline Matéria seca (\%) & 29,2 & 18,2 & 88,3 \\
Proteína bruta & 1 & 3,0 & 13,8 \\
$\mathrm{CNF}^{1}$ & 3,8 & 36,1 & 47,3 \\
$\mathrm{FDN}^{1}$ & 12,2 & 56,7 & 49,9 \\
$\mathrm{FDA}^{1}$ & 79,2 & 32,7 & 39,0 \\
$\mathrm{NIDN}^{2}$ & 52,5 & 48,9 & 59,0 \\
$\mathrm{NIDA}^{2}$ & 45,0 & 10,0 & 32,7 \\
Cinza & 9,3 & 7,4 & 4,8 \\
\hline
\end{tabular}

$\mathrm{CNF}=$ carboidratos não fibrosos, $\mathrm{FDN}=$ fibra em detergente neutro, $\mathrm{FDA}=$ fibra em detergente ácido, NIDN= nitrogênio insolúvel em detergente neutro, NIDA= nitrogênio insolúvel em detergente ácido.

${ }^{1} \%$ da MS, ${ }^{2} \%$ do N total.

O delineamento experimental adotado foi inteiramente ao acaso, em esquema fatorial $2 \times 4$, com quatro repetições. Ao capim-elefante foram adicionados 0, 15, 30 e 45\% de cana-de-açúcar, com base na matéria natural, sem inclusão de farelo de cacau, e as mesmas doses para as silagens que receberam $15 \%$ de farelo de cacau, com base na matéria natural.

O capim-elefante aos 120 dias de crescimento, contendo $29,2 \%$ de MS, e a cana-de-açúcar aos 12 meses de idade, com 18,2\% de MS, colhidos manualmente a $10 \mathrm{~cm}$ do solo, foram picados em fragmentos de $2 \mathrm{~cm}$, em ensiladeira estacionária.

Foram utilizados 32 silos experimentais de PVC, com $50 \mathrm{~cm}$ de altura por $10 \mathrm{~cm}$ de diâmetro, providos de válvula de Bunsen, com areia e tela no fundo, previamente pesados, para captar o efluente desprendido da silagem. O material foi compactado adotando-se a densidade de $600 \mathrm{~kg}$ de silagem $/ \mathrm{m}^{3}$; posteriormente, os silos foram vedados e pesados. Após 60 dias de armazenamento, foram novamente pesados para 
avaliação das perdas por gases e, em seguida, abertos para a retirada da silagem e pesagem da areia do fundo do silo para calcular as perdas por efluente.

A taxa de recuperação de MS foi calculada segundo a equação sugerida por Loures et al. (2004).

Após a abertura dos silos, o material foi retirado e homogeneizado, para colheita de amostras, que foram divididas em duas porções, Uma porção, retirada imediatamente após a abertura dos silos, foi destinada à determinação do nitrogênio amoniacal e do $\mathrm{pH}$, segundo a metodologia de Bolsen et al. (1992).

Os resultados foram submetidos à análise de variância, considerando como fontes de variação a adição de farelo de cacau, de cana-de-açúcar e a interação desses fatores. A interação foi desdobrada, ou não, de acordo com a sua significância. $\mathrm{O}$ efeito da adição da cana-de-açúcar foi avaliado por análise de regressão, por meio de polinômios ortogonais, pela decomposição da respectiva soma de quadrado em efeitos linear, quadrático e cúbico. Também foram estimados os coeficientes de determinação. A adição de farelo de cacau, por se tratar de apenas dois níveis, foi comparada pelo teste F. Para realizar as análises estatísticas, foi utilizado o programa SAEG (Sistema..., 2001).

\section{RESULTADOS E DISCUSSÃO}

$\mathrm{Na}$ Tab. 2 apresenta-se a significância do efeito da adição de farelo de cacau (F), cana-de-açúcar (C) e da interação $\mathrm{F}$ x C sobre algumas características da silagem de capim-elefante. Houve efeito $(\mathrm{P}<0,01)$ da interação para a taxa de recuperação da $\mathrm{MS}, \mathrm{pH}$ e perdas por efluente.

Tabela 2 . Nível de significância do efeito da adição de farelo de cacau (F), cana-de-açúcar (C) ou da interação F x C para matéria seca (MS), taxa de recuperação da MS (RMS), $\mathrm{pH}$, nitrogênio amoniacal $\left(\mathrm{N}-\mathrm{NH}_{3}\right)$, perdas por efluente e por gases da silagem de capim-elefante

\begin{tabular}{|c|c|c|c|c|c|c|c|}
\hline Fonte de variação & GL & MS & $\mathrm{RMS}^{1}$ & $\mathrm{pH}$ & $\mathrm{N}-\mathrm{NH}_{3}{ }^{2}$ & Efluente $^{3}$ & Gases \\
\hline Farelo de cacau $(\mathrm{F})$ & 1 & $* *$ & & & $* *$ & & $* *$ \\
\hline Cana-de-açúcar (C) & 3 & $* *$ & & & & & $* *$ \\
\hline Interação C x F & 3 & ns & $* *$ & $* *$ & ns & $* *$ & $\mathrm{~ns}$ \\
\hline Resíduo & 24 & & & & & & \\
\hline CV (\%) & & 2,5 & 2,2 & 2,8 & 5,9 & 22,2 & 13,0 \\
\hline
\end{tabular}

** Significativo a $1 \%$ de probabilidade pelo teste $\mathrm{F}$.

$1 \%$ da MS; ${ }^{2} \%$ do nitrogênio total; ${ }^{3} \mathrm{~kg} / \mathrm{t}$ de matéria natural.

Embora os teores de MS do material ensilado apenas com adição de cana-de-açúcar encontrem-se abaixo da faixa considerada ideal, de 30 a $40 \%$, conforme sugerido por Silveira (1987) como necessária para garantir produção de silagens de boa qualidade, a adição de $15 \%$ de farelo de cacau resultou em aumento médio $(\mathrm{P}<0,01)$ de 27,7 para $34,7 \%$ de MS nas silagens (Tab. 3). Esse aditivo promoveu incremento de $0,47 \%$ de MS por unidade percentual de farelo de cacau incluído, próximo aos $0,49 \%$ estimados por Teixeira et al. (2005), ao adicionarem farelo de cacau na ensilagem do capim-elefante com $18,9 \%$ de MS. Foi verificada redução linear $(\mathrm{P}<0,01)$ do teor de MS com a adição de cana-de-açúcar. De acordo com Van Soest (1994), o aumento no teor de MS provoca maior pressão osmótica do meio, tornando o ambiente desfavorável para o desenvolvimento e a atividade metabólica das leveduras.

O etanol produzido nas silagens contendo cana-deaçúcar pode acarretar perdas de até $48 \%$ da MS (McDonald et al., 1991). Contudo, a inclusão de cana-de-açúcar nas silagens que receberam farelo de cacau manteve média de $95,3 \%$ de taxa de recuperação da MS (Fig. 1), estimando-se uma perda de $4,6 \%$ de MS, o que indica que a elevação do teor de MS provocada pelo farelo de cacau para níveis adequados evitou maiores perdas de MS do material ensilado. As perdas encontradas podem ser consideradas baixas para as doses de cana-deaçúcar estudadas, quando comparadas com os $22,4 \%$ de perdas de MS encontrados por Freitas et al. (2006), que incluíram resíduo de soja em silagem de cana-de-açúcar, e os $29 \%$ de perdas de MS verificados por Kung Jr. e Stanley (1982) para cana-de-açúcar ensilada aos 15 meses de crescimento. Considerando a taxa média de recuperação da MS das silagens com inclusão de farelo de cacau como perdas aceitáveis, doses acima de 22,4\% de cana-de-açúcar aumentariam consideravelmente as perdas de MS, comprometendo o processo de fermentação da silagem. Entretanto, podem-se recomendar doses de $45 \%$ de cana-de-açúcar desde que se utilizem 15\% de farelo de cacau. 
Tabela 3. Teor de matéria seca da silagem de capim-elefante aditivado com farelo de cacau e cana-deaçúcar: equação de regressão e coeficiente de determinação $\left(\mathrm{R}^{2}\right)$

\begin{tabular}{ccccccccc}
$\begin{array}{c}\text { Farelo de cacau } \\
(\% \mathrm{MN})\end{array}$ & \multicolumn{3}{c}{ Cana-de-açúcar $(\% \mathrm{MN})$} & Média & Equação de regressão & $\mathrm{R}^{2}$ \\
\cline { 2 - 5 } & 0 & 15 & 30 & 45 & & & \\
\hline 0 & 29,9 & 29,6 & 26,4 & 25,0 & $27,7 \mathrm{~b}$ & & \\
\hline 15 & 37,1 & 35,9 & 32,6 & 33,1 & $34,7 \mathrm{a}$ & & \\
\hline Média & 33,5 & 32,7 & 29,5 & 29,0 & 31,2 & $\hat{\mathrm{Y}}=33,6953-0,11069^{* *} \mathrm{X}$ & 0,91
\end{tabular}

Médias seguidas de letras distintas na coluna diferem entre si pelo teste $\mathrm{F}(\mathrm{P}<0,01)$.

** Significativo a $1 \%$ de probabilidade pelo teste "t".

$\% \mathrm{MN}=\%$ da matéria natural.

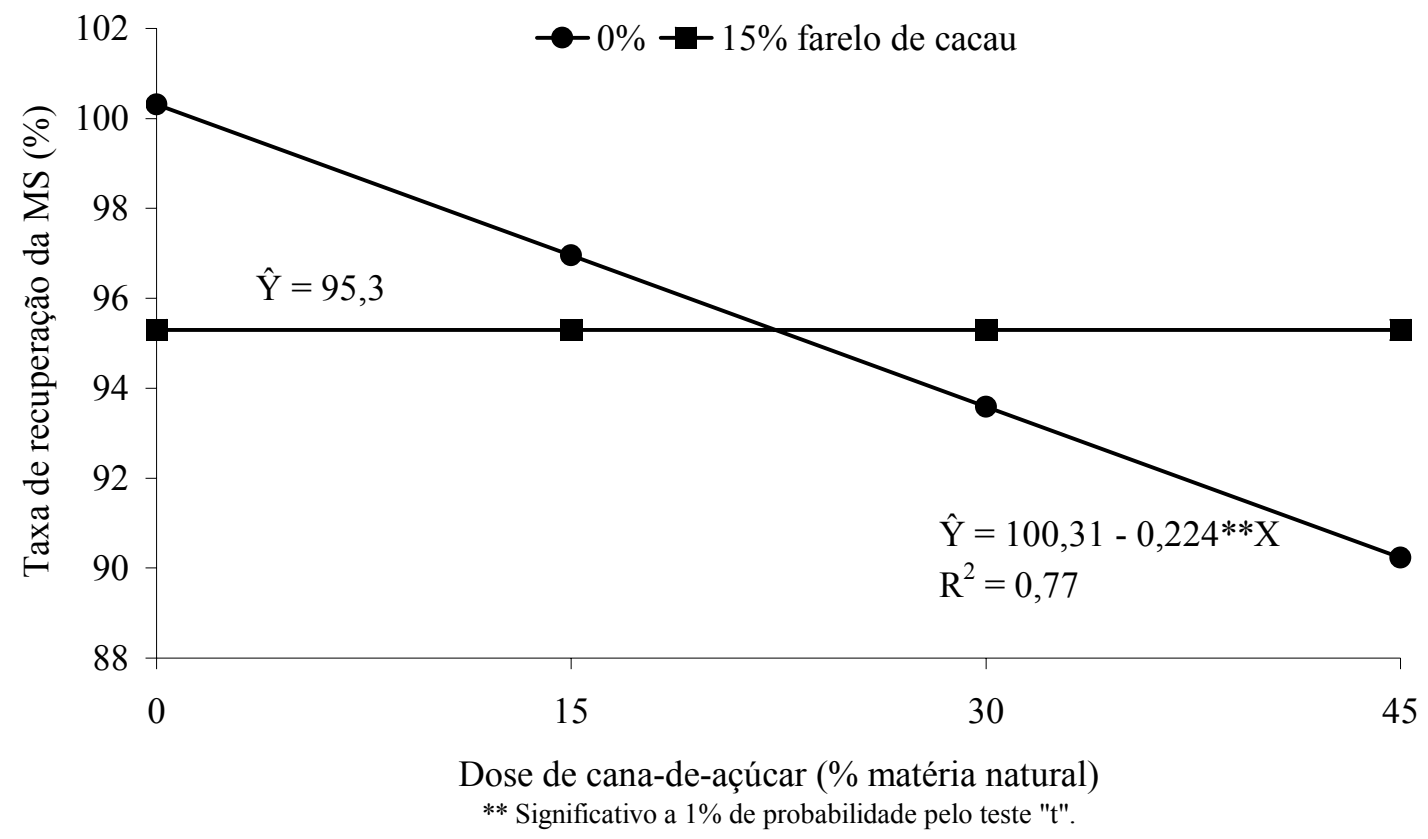

Figura 1. Taxa de recuperação da matéria seca de silagens de capim-elefante aditivado com cana-deaçúcar e farelo de cacau.

Foi observado aumento $(\mathrm{P}<0,01)$ linear nas perdas por efluente com a inclusão de cana-deaçúcar nos tratamentos sem farelo de cacau, estimando-se perdas de $1,3 \mathrm{~kg} / \mathrm{t}$ por unidade percentual de cana-de-açúcar adicionada, quantidade muito elevada, levando-se em conta que o efluente perdido carreia os nutrientes em água, representando prejuízos no valor nutritivo das silagens. Desdobrando o efeito do farelo de cacau dentro das doses de cana-de-açúcar, foram verificadas reduções significativas $(\mathrm{P}<0,01)$ de 68,$6 ; 83,4$ e $88,8 \%$ da produção de efluente para as silagens com 15,30 e $45 \%$ de cana-de-açúcar, respectivamente, quando se adicionou o farelo de cacau (Tab. 4). Hameleers et al. (1999) verificaram que a polpa de beterraba reduziu a produção de efluente em silagens de milho, e Bernardino et al. (2005) concluíram que proporções maiores que $20 \%$ de casca de café foram suficientes para eliminar toda a produção de efluente das silagens de capim-elefante.

A perda de CS na forma de gases, durante a fermentação, resulta também na produção de água, diminuindo o teor de MS da forragem. Pode-se deduzir que a adição de cana-de-açúcar às silagens sem farelo de cacau foi responsável pela maior perda por efluente. 
Tabela 4. Perdas por efluente em kg/t de MN das silagens de capim-elefante aditivado com cana-de-açúcar e farelo de cacau: equações de regressão e coeficiente de determinação $\left(\mathrm{R}^{2}\right)$

\begin{tabular}{|c|c|c|c|c|c|c|c|}
\hline \multirow{2}{*}{$\begin{array}{c}\text { Farelo de cacau } \\
\qquad(\% \mathrm{MN})\end{array}$} & \multicolumn{4}{|c|}{ Cana-de-açúcar (\% MN) } & \multirow{2}{*}{ Média } & \multirow{2}{*}{ Equação de regressão } & \multirow{2}{*}{$\mathrm{R}^{2}$} \\
\hline & 0 & 15 & 30 & 45 & & & \\
\hline 0 & $9,5 \mathrm{a}$ & $13,7 \mathrm{a}$ & $37,3 \mathrm{a}$ & $66,0 \mathrm{a}$ & 31,6 & $\hat{\mathrm{Y}}=2,6593+1,2871 * \mathrm{X}$ & 0,92 \\
\hline 15 & $5,4 \mathrm{a}$ & $4,3 \mathrm{~b}$ & $6,2 b$ & $7,4 b$ & 5,8 & $\hat{\mathrm{Y}}=5,81$ & \\
\hline Média & 7,5 & 9,0 & 21,7 & 36,7 & 18,7 & & \\
\hline
\end{tabular}

Médias seguidas de letras distintas na coluna diferem entre si pelo teste $\mathrm{F}(\mathrm{P}<0,01)$.

** Significativo a $1 \%$ de probabilidade pelo teste " $t "$.

$\% \mathrm{MN}=\%$ da matéria natural.

O capim-elefante que foi ensilado sem adição de farelo de cacau sofreu as maiores perdas por gases, em média $6,3 \%$ da MS, e, quando se adicionou o farelo de cacau, essas perdas reduziram-se $(\mathrm{P}<$ 0,01 ) para $4,7 \%$ da MS (Tab. 5). A maior causa de perda de MS na silagem de cana-de-açúcar é a reação bioquímica da produção de etanol, em que a MS é catalisada via fermentação pelas leveduras, de modo que cada molécula de glicose fermentada gera duas moléculas de etanol, duas de dióxido de carbono e duas de água (Rodrigues et al., 2005). As menores perdas com a inclusão do farelo de cacau podem ser explicadas pelo aumento do teor de MS das silagens. Por outro lado, a cana-de-açúcar, por possuir alto conteúdo de CS, elevou as perdas por gases que estão relacionadas com as perdas de MS observadas com a redução da taxa de recuperação da MS.

Tabela 5. Perdas por gases em porcentagem da matéria seca das silagens de capim-elefante aditivado com cana-de-açúcar e farelo de cacau: equações de regressão e coeficiente de determinação $\left(\mathrm{R}^{2}\right)$

\begin{tabular}{ccccccccc} 
Farelo de cacau & \multicolumn{5}{c}{ Cana-de-açúcar $(\% \mathrm{MN})$} & \multirow{2}{*}{ Média } & Equação de regressão & $\mathrm{R}^{2}$ \\
\cline { 2 - 5 }$(\% \mathrm{MN})$ & 0 & 15 & 30 & 45 & & & \\
\hline 0 & 5,1 & 5,8 & 6,9 & 7,3 & $6,3 \mathrm{a}$ & & \\
15 & 3,2 & 4,0 & 5,8 & 5,9 & $4,7 \mathrm{~b}$ & & \\
Média & 4,1 & 4,9 & 6,3 & 6,6 & 5,5 & $\hat{\mathrm{Y}}=4,15474+0,05901 * * \mathrm{X}$ & 0,94 \\
\hline
\end{tabular}

Médias seguidas de letras distintas na coluna diferem entre si pelo teste $\mathrm{F}(\mathrm{P}<0,01)$.

**Significativo a $1 \%$ de probabilidade pelo teste " $t$ ".

$\% \mathrm{MN}=\%$ da matéria natural.

A variação do $\mathrm{pH}$, de 3,7 a 4,1 , encontra-se próxima da faixa ótima de 3,8 a 4,2, recomendada por McDonald (1981) para uma fermentação adequada. Resultados semelhantes foram encontrados por Freitas et al. (2006), cuja variação foi de 3,5 a 3,9 , quando utilizaram resíduos da soja em silagens de cana-de-açúcar. A adição de farelo de cacau manteve o $\mathrm{pH}$ em 4,1 para todos os níveis de cana-de-açúcar adicionados, estimando-se pela equação de regressão, $\hat{Y}=4,15474+0,05901 * * X$, a adição de até $26,2 \%$ de cana-de-açúcar, para os tratamentos sem a presença do farelo de cacau, para se obter $\mathrm{pH}$ dentro da faixa recomendada (Tab. 6).

Tabela 6. Valores de $\mathrm{pH}$ das silagens de capim-elefante aditivado com cana-de-açúcar e farelo de cacau: equações de regressão e coeficiente de determinação $\left(\mathrm{R}^{2}\right)$

\begin{tabular}{ccccccccc}
\hline \multirow{2}{*}{$\begin{array}{c}\text { Farelo de cacau } \\
(\% \mathrm{MN})\end{array}$} & \multicolumn{4}{c}{ Cana-de-açúcar $(\% \mathrm{MN})$} & Média & Equação de regressão & $\mathrm{R}^{2}$ \\
\cline { 2 - 5 } & 0 & 15 & 30 & 45 & & & \\
\hline 0 & $4,2 \mathrm{a}$ & $3,8 \mathrm{~b}$ & $3,7 \mathrm{~b}$ & $3,7 \mathrm{~b}$ & 3,8 & $\hat{\mathrm{Y}}=4,08525-0,0109 * * \mathrm{X}$ & 0,83 \\
15 & $4,1 \mathrm{a}$ & $4,1 \mathrm{a}$ & $4,1 \mathrm{a}$ & $4,1 \mathrm{a}$ & 4,1 & $\hat{\mathrm{Y}}=4,1$ & \\
Média & 4,1 & 4,0 & 3,9 & 3,9 & & 4,0 & & \\
\hline
\end{tabular}

Médias seguidas de letras distintas na coluna diferem entre si pelo teste $\mathrm{F}(\mathrm{P}<0,01)$.

** Significativo a $1 \%$ de probabilidade pelo teste " $t$ ".

$\% \mathrm{MN}=\%$ da matéria natural. 
Houve redução linear $(\mathrm{P}<0,01)$ do $\mathrm{pH}$, na medida em que foi adicionada cana-de-açúcar na ensilagem do capim-elefante. Quando se trabalha com forragens com altos teores de açúcares e baixos de proteína, a estabilidade do $\mathrm{pH}$ ocorre, normalmente, antes do $10^{\circ}$ dia de ensilagem, destacando-se que o estímulo à fermentação pode ser prejudicial no processo de ensilagem, pois aumenta o consumo de CS e mostra que o desenvolvimento das leveduras não é inibido apenas pelo declínio do $\mathrm{pH}$ das silagens (McDonald et al., 1991). Assim, a redução do pH das silagens sem farelo de cacau pode ser explicada pelos altos teores de CS. Ferreira et al. (2007), ao observarem redução de 22,6 para $9,0 \%$ de CS durante os sete primeiros dias da ensilagem da cana-de-açúcar, sugeriram rápida fermentação desses CS que contribuem para a redução do $\mathrm{pH}$. Entretanto, os resultados demonstraram que somente a redução do pH não foi capaz de evitar as perdas por gases, nitrogênio amoniacal e efluente das silagens sem a inclusão de farelo de cacau.

Apenas as silagens adicionadas de farelo de cacau apresentaram teores de nitrogênio amoniacal dentro da faixa ideal, média de 3,9\% do N-total, se se considerar silagens com teores de nitrogênio amoniacal abaixo de $8 \%$ como de boa qualidade (Silveira, 1975), enquanto as silagens que não continham farelo de cacau tiveram perdas de nitrogênio amoniacal da ordem de $13,6 \%$, em média, do $\mathrm{N}$ total. Isso foi um indicativo de silagem de baixa qualidade (Tab.
7). Apesar do baixo teor de PB dos tratamentos sem adição de farelo de cacau, os valores de nitrogênio amoniacal foram considerados elevados, pois, segundo Van Soest (1994), valores acima de $10 \%$ indicam que o processo de fermentação resultou em quebra excessiva de proteína em amônia.

Estimou-se que a adição de farelo de cacau promoveu redução $(\mathrm{P}<0,01)$ de $71 \%$ das perdas por nitrogênio amoniacal, resultado mais alto que os $60 \%$ encontrados por Freitas et al. (2006), que utilizaram resíduo da colheita da soja. Ferrari Jr. e Lavezzo (2001) não verificaram efeito da adição de até $12 \%$ de farelo de mandioca em silagem de capim-elefante com 18,7\% de MS, e Bernardino et al. (2005) observaram decréscimo do teor de nitrogênio amoniacal, à medida que se adicionou casca de café em silagem de capimelefante. Segundo Evangelista et al. (2004), o valor do $\mathrm{pH}$, juntamente com o nitrogênio amoniacal, fornece indicação da forma como se processa a fermentação. A redução da concentração de nitrogênio amoniacal com a inclusão do farelo de cacau pode ser explicada pela diminuição do teor de MS, que teria reduzido a atividade de bactérias do gênero Clostridium, promotoras da proteólise e da liberação do nitrogênio amoniacal durante $o$ processo de ensilagem. Pode-se afirmar que o farelo de cacau melhorou as características fermentativas da silagem, pois, juntamente com o $\mathrm{pH}$, manteve o nitrogênio amoniacal dentro da faixa adequada, 4,1 e 3,9\%, respectivamente.

Tabela 7. Concentração de nitrogênio amoniacal das silagens de capim-elefante aditivado com cana-deaçúcar e farelo de cacau: equação de regressão

\begin{tabular}{ccccccc}
\multirow{2}{*}{$\begin{array}{c}\text { arelo de cacau } \\
(\% \mathrm{MN})\end{array}$} & \multicolumn{4}{c}{ Cana-de-açúcar $(\% \mathrm{MN})$} & \multirow{2}{*}{ Média } & Equação de regressão \\
\cline { 2 - 5 } & 0 & 15 & 30 & 45 & & \\
\hline 0 & 14,7 & 13,0 & 13,6 & 13,1 & $13,6 \mathrm{a}$ & \\
15 & 3,9 & 3,9 & 3,8 & 4,0 & $3,9 \mathrm{~b}$ & $\hat{\mathrm{Y}}=8,8$ \\
Média & 9,3 & 8,4 & 8,7 & 8,6 & 8,8 & \\
\hline
\end{tabular}

Médias seguidas de letras distintas na coluna diferem entre si pelo teste $\mathrm{F}(\mathrm{P}<0,05)$.

$\% \mathrm{MN}=\%$ da matéria natural.

\section{CONCLUSÕES}

O farelo de cacau é eficaz na redução da umidade e da concentração de nitrogênio amoniacal das silagens de capim-elefante. A inclusão de até $22,4 \%$ da cana-de-açúcar na ensilagem de capim-elefante evita perdas excessivas de matéria seca. A associação de farelo de cacau e cana-de-açúcar permite manter alta taxa de recuperação da matéria seca, o que reduz as perdas de matéria seca e de efluentes e mantém o pH estável, favorecendo o processo fermentativo da silagem de capim-elefante. Recomenda-se a dose de até $22,4 \%$ de cana-de- 
açúcar, cv - IAC86 - 2480, na ensilagem de capim-elefante com $29 \%$ de matéria seca, podendo-se aumentar para $45 \%$, desde que se utilizem $15 \%$ de farelo de cacau.

\section{REFERÊNCIAS BIBLIOGRÁFICAS}

ANDRADE, S.J.T.; MELOTTI, L. Efeito de alguns tratamentos sobre a qualidade da silagem de capimelefante cultivar Napier (Pennisetum purpureum, Schum). Braz. J. Vet. Res. Anim. Sci., v.41, p.409-415, 2004.

BERNARDINO, F.S.; GARCIA, R.; ROCHA, F.C. et al. Produção e características do efluente e composição bromatológica da silagem de capim-elefante contendo diferentes níveis de casca de café. Rev. Bras. Zootec., v.34, supl., p.2185-2191, 2005.

BOLSEN, K.K.; LIN, C.; BRENT, B.E. et al. Effect of silage additives on the microbial succession and fermentation process of alfalfa and corn silages. J. Dairy Sci., v.75, p.3066-3083, 1992.

EVANGELISTA, A.R.; PERON, A.J.; AMARAL, P.N.C. Forrageiras não convencionais para silagem - mitos e realidades. In: SIMPÓSIO SOBRE MANEJO ESTRATÉGICO DA PASTAGEM, 2., 2004, Viçosa. Anais... Viçosa: Universidade Federal de Viçosa, 2004. p.463-507.

FERRARI Jr. E.; LAVEZZO, W. Qualidade da silagem de capim-elefante (Pennisetum purpureum Schum.) emurchecido ou acrescido de farelo de mandioca. Rev. Bras. Zootec., v.30, p.1424-1431, 2001.

FERREIRA, D.A.; GONÇALVES, L.C.; MOLINA, L.R. et al. Características de fermentação da silagem de canade-açúcar tratada com uréia, zeólita, inoculante bacteriano e inoculante bacteriano/enzimático. Arq. Bras. Med. Vet. Zootec., v.59, p.423-433, 2007.

FREITAS, A.W.P.; PEREIRA, J.C.; ROCHA, F.C. et al. Avaliação da qualidade nutricional da silagem de canade-açúcar com aditivos microbianos e enriquecida com resíduo da colheita de soja. Rev. Bras. Zootec., v.35, p.3847, 2006.

HAMELEERS, A.; LEACH, K.A.; OFFER, N.W. et al. The effects of incorporating sugar beet pulp with forage maize at ensiling on silage fermentation and effluent output using drum silos. Grass Forage Sci., v.54, p.322335, 1999.

KUNG JR, L.; STANLEY, R.W. Effect of stage of maturity on the nutritive value of whole-plant sugarcane preserved as silage. J. Anim. Sci., v.54, p.689-796, 1982.

LOURES, D.R.S.; NUSSIO, L.G.; PAZIANI, S.F. et al. Perdas por efluente e gases em silagens de capim Tanzânia sob os efeitos do teor de matéria seca, tamanho de partícula e do uso de aditivos. In: REUNIÃO ANUAL DA SOCIEDADE BRASILEIRA DE ZOOTECNIA, 41., 2004,Campo Grande. Anais... São Paulo: SBZ, 2004. CDROM. Forragicultura. FOR-133.
McDONALD, P. (Ed). The biochemistry of silage. New York: John Wiley e Sons, 1981. 226p.

McDONALD, P.; HENDERSON, A.R.; HERON, S.J.E. (Eds). The biochemistry of silage. 2.ed. Marlow: Chalcomb Publications, 1991. 340p.

NUSSIO, L.G.; SCHIMDT, P.; PEDROSO, A.F. Silagem de cana-de-açúcar. In: SIMPÓSIO DE FORRAGICULTURA E PASTAGENS: TEMAS EM EVIDÊNCIA - SUSTENTABILIDADE, 2003, Lavras. Anais... Lavras: UFLA, 2003. p.49-74.

PIRES, A.J.V.; CARVALHO JÚNIOR, J.N., SILVA, F.F. et al. Farelo de cacau (Theobroma cacao) na alimentação de ovinos. In: REUNIÃO ANUAL DA SOCIEDADE BRASILEIRA DE ZOOTECNIA, 39. 2002. Recife. Anais... Recife: SBZ, 2002. CD-ROM. Nutrição de Ruminantes.

RODRIGUES, P.H.M.; BORGATTI, L.M.O.; GOMES, R.W. et al. Efeito da adição de níveis crescentes de polpa cítrica sobre a qualidade fermentativa e o valor nutritivo da silagem de capim-elefante. Rev. Bras. Zootec., v.34, p.1138-1145, 2005.

SILVEIRA, A.C. Produção e utilização de silagens. In: SEMANA DE ZOOTECNIA, 12., 1987, Pirassununga. Anais... Pirassununga: Fundação Cargill, 1987. p.119134.

SILVEIRA, A.C. Técnicas para produção de silagens. In: SIMPÓSIO SOBRE MANEJO DE PASTAGENS, 2. , 1975, Piracicaba. Anais... Piracicaba: ESALQ, 1975. p.156-180.

SISTEMA de análises estatísticas - SAEG. Viçosa, MG: UFV, 2001.301p.

TEIXEIRA, F.A.; SANTOS, L.C.; NASCIMENTO, P.V.N. et al. Perdas por nitrogênio amoniacal em silagem de capim-elefante (Penninsetum purpureum Schum) acrescido de farelo de cacau (Theobroma cacao). Rev. Elect. Vet., 2005. Disponível em $<\mathrm{http}: / /$ www.veterinaria.org/

revistas/redvet/n111105.html/>. Acessado em 12 abr. 2005.

TOSI, P.; MATTOS, W.R.S.; TOSI, H. et al. Avaliação do capim-elefante (Pennisetum purpureum Schum.) cultivar taiwan a-148, ensilado com diferentes técnicas de redução de umidade. Rev. Bras. Zootec., v.28, p.947-954, 1999.

VAN SOEST, P.J. (Ed). Nutritional ecology of the ruminant. 2.ed. New York: Cornell University, 1994. $476 \mathrm{p}$

VELLOSO, L.; ROCHA, G. L.; FARIA, V. P. Avaliação de silagens de milho com ou sem aditivo, pelo sistema Flieg. Bol. Ind. Anim., v.30, p.245-251, 1973.

WOOLFORD, M.K. (Ed). The silage fermentation. New York: Marcel Dekker, 1984. 350p. 